\title{
Transcriptional Control of Glutaredoxin GRXC9 Expression by a Salicylic Acid-Dependent and NPR1-Independent Pathway in Arabidopsis
}

\author{
Ariel Herrera-Vásquez • Loreto Carvallo • Francisca Blanco • Mariola Tobar • \\ Eva Villarroel-Candia • Jesús Vicente-Carbajosa • Paula Salinas • Loreto Holuigue
}

Published online: 14 August 2014

(C) The Author(s) 2014. This article is published with open access at Springerlink.com

\begin{abstract}
Salicylic acid (SA) is a key hormone that mediates gene transcriptional reprogramming in the context of the defense response to stress. GRXC9, coding for a CC-type glutaredoxin from Arabidopsis, is an SA-responsive gene induced early and transiently by an NPR1-independent pathway. Here, we address the mechanism involved in this SAdependent pathway, using $G R X C 9$ as a model gene. We first established that GRXC9 expression is induced by UVB exposure through this pathway, validating its activation in a physiological stress condition. GRXC9 promoter analyses indicate that SA controls gene transcription through two activating sequence-1 (as-1)-like elements located in its proximal region. TGA2 and TGA3, but not TGA1, are constitutively bound to this promoter region. Accordingly, the transient recruitment of RNA polymerase II to the GRXC9 promoter, as well as the transient accumulation of gene transcripts detected in SAtreated WT plants, was abolished in a knockout mutant for the TGA class II factors. We conclude that constitutive binding of TGA2 is essential for controlling GRXC9 expression,
\end{abstract}

The present address of Dra. Francisca Blanco is Centro de Biotecnologia Vegetal, Facultad de Ciencias Biológicas, Universidad Andrés Bello, Chile.

Electronic supplementary material The online version of this article (doi:10.1007/s11105-014-0782-5) contains supplementary material, which is available to authorized users.

A. Herrera-Vásquez • L. Carvallo · F. Blanco · M. Tobar ·

E. Villarroel-Candia $\cdot$ P. Salinas $\cdot$ L. Holuigue $(\triangle)$

Departamento de Genética Molecular y Microbiología, Facultad de

Ciencias Biológicas, Pontificia Universidad Católica de Chile,

Alameda 340, Santiago, Chile

e-mail: lholuigue@bio.puc.cl

J. Vicente-Carbajosa

Centro de Biotecnología y Genómica de Plantas (UPM-INIA),

Universidad Politécnica de Madrid, 28223 Pozuelo de Alarcón,

Madrid, Spain while binding of TGA3 in a lesser extent contributes to this regulation. Finally, overexpression of GRXC9 indicates that the GRXC9 protein negatively controls its own gene expression, forming part of the complex bound to the as-1-containing promoter region. These findings are integrated in a model that explains how SA controls transcription of GRXC9 in the context of the defense response to stress.

Keywords as-1-like element · Glutaredoxin GRXC9 $(G R X 480) \cdot$ NPR1-independent · Salicylic acid · TGA transcription factors

\section{Introduction}

Salicylic acid (SA) is a key plant hormone involved in stress defense responses against a wide range of biotrophic and hemibiotrophic pathogens and abiotic stress conditions such as UV, high light radiation, ozone exposure, salinity, osmotic, and drought stress (Borsani et al. 2001; Garcion et al. 2008; Lee et al. 2010; Mateo et al. 2006; Miura et al. 2013; Wildermuth et al. 2001; Nawrath and Metraux 1999; Ogawa et al. 2005). In response to stress, SA triggers a global transcriptional reprogramming in the infected/ damaged tissues, as well as in the neighboring cells, orchestrating local and systemic defense responses (Vlot et al. 2009; Fu and Dong 2013).

Recent reports support evidence that SA interplays with redox signals, such as $\mathrm{H}_{2} \mathrm{O}_{2}$ and glutathione, in the modulation of the defense response (Foyer and Noctor 2011; Dubreuil-Maurizi and Poinssot 2012; Noshi et al. 2012; Han et al. 2013). Although this interplay is being increasingly recognized (Fu and Dong 2013), the precise mechanisms that govern this relationship are still unknown. We previously 
reported that a subset of the early SA-inducible genes (early SAIGs) code for enzymes with glutathione (GSH)-dependent antioxidant and detoxifying activities, such as glutaredoxins $(G R X)$ and glutathione $S$-transferases (GST) (Blanco et al. 2005, 2009). Moreover, we showed that the expression of GRXS13, one of the GRXS coded by early SAIGs, is critical for limiting basal and high light stress-induced reactive oxygen species (ROS) production and for regulation of the ascorbate/dehydroascorbate (ASC/DHA) ratio after stress (Laporte et al. 2012). These data support the idea that these genes could be involved in the ROS-scavenging/antioxidant network that contains the oxidative burst produced under stress conditions.

Here, we studied GRXC9 (also known as GRX480), a second $G R X$ gene identified as an early SAIG (Blanco et al. 2009). The GRXS13 and GRXC9 genes code for glutaredoxins belonging to the plant-specific CC-type in Arabidopsis (Ndamukong et al. 2007; La Camera et al. 2011; Laporte et al. 2012). Glutaredoxins are small disulfide oxidoreductases that catalyze the reduction of disulfide bridges and protein-GSH adducts ( $S$ glutathionylated proteins) using the reducing power of GSH and NADPH (Rouhier et al. 2008). In this work, we specifically focus in unrevealing the transcriptional control mechanisms of GRXC9 by SA.

Transcriptional activation of the majority of the SAIGs, including the pathogenesis-related 1 gene $(P R-1$ gene, the most frequently used marker gene for SA signaling) is mediated by the master coactivator nonexpressor of pathogenesisrelated genes 1 (NPR1) (Fu and Dong 2013; Dong 2004). SA controls the nuclear targeting and activity of the NPR1 protein, via posttranslational modifications and degradation $(\mathrm{Fu}$ et al. 2012; Mou et al. 2003; Tada et al. 2008). Recently, the NPR1 paralogs NPR3 and NPR4 were identified as direct receptors of SA that regulate NPR1 degradation, controlling in this way the SA responses mediated by this coactivator (Fu et al. 2012). On the other hand, there is a second pathway that leads to the early and transient activation of SAIGs, via a NPR1-independent mechanism, as we and other groups have previously reported (Lieberherr et al. 2003; Uquillas et al. 2004; Blanco et al. 2005, 2009; Fode et al. 2008; LangloisMeurinne et al. 2005; Shearer et al. 2012). The mechanism by which SA activates the expression of these early SAIGs is still unknown. In this work, we assess this mechanism using GRXC9 as a model for the SA-dependent and NPR1independent pathway that controls defense gene expression.

Promoter analyses of early SAIGs show overrepresentation of a cis-acting element with high homology to the activating sequence-1 (as-1) (Blanco et al. 2005, 2009). The $a s-1$ element consists of two adjacent variants of the palindromic sequence TGAC/GTCA (TGACG box), separated by four base pairs (Ellis et al. 1993; Krawczyk et al. 2002). The as-1 element was first identified in the Cauliflower Mosaic Virus 35S (CaMV 35S) promoter, as an element that conferred basal expression in root tips (Benfey et al. 1989). Subsequent studies showed that the as- 1 element from the CaMV 35S promoter responds early and transiently to SA (Qin et al. 1994), to xenobiotic compounds like the synthetic auxin 2,4dichlorophenoxyacetic acid (2,4D) (Johnson et al. 2001), and to $\mathrm{H}_{2} \mathrm{O}_{2}$ and methyl viologen (Garreton et al. 2002). Accordingly, this particular array of two adjacent TGACG boxes has been found overrepresented, not only in early SAIGs promoters (Blanco et al. 2005, 2009) but also in the promoters of plant genes associated to chemical detoxification process induced by xenobiotic chemicals like 2,4-D and oxidized lipids (oxilipins) (Fode et al. 2008; Köster et al. 2012; Johnson et al. 2001).

TGACG boxes are recognized by basic leucine zipper (bZIP) factors of the TGA family, which has 10 members in Arabidopsis (Jakoby et al. 2002; Gatz 2012). Seven of these factors have been associated to the defense response (TGA1TGA7), being class II (TGA2, TGA5, and TGA6) the most relevant for the SA pathway (Gatz 2012). In fact, involvement of TGA class II factors in the canonic pathway that controls expression of SA- and NPR1-dependent genes containing TGA motifs in their promoters has been extensively reported using the Arabidopsis PR-1 gene as a model (Lebel et al. 1998; Kesarwani et al. 2007). In contrast, the pathway that activates SA-dependent and NPR1-independent genes containing the as-1-like element in their promoters has been far less explored.

In this work, we show evidence that GRXC9 expression is activated by stress, such as UVB radiation, via an SA-dependent and NPR1-independent pathway. Bioinformatics analysis of the GRXC9 promoter indicates the presence of two putative as-1-like elements in its proximal region. We show that both elements are functionally relevant and required for the SA-mediated induction of the gene. Moreover, our data indicate that TGA2 and TGA3, but not TGA1, are constitutively bound to the GRXC9 promoter in vivo. We also confirm the requirement of TGA class II factors for the recruitment of the RNA polymerase II (Pol II) enzyme to the basal promoter and for the transcriptional induction of the gene upon SA stimuli. Analysis of the transactivation as well as the homodimerization and heterodimerization ability of TGA class II and TGA3 factors gives further insights into the mechanism of induction of antioxidant genes by the SA/TGA2-3/as1-like pathway. Interestingly, we show evidence indicating that GRXC9 participates in the control of the expression of its own gene, suggesting its involvement in the transient activation of early SAIGs. Physiological and mechanistic implications of these findings are discussed. 


\section{Results}

GRXC9 Gene Expression Is Induced by UVB Exposure, via an SA-Dependent and NPR1-Independent Mechanism

We previously reported that $G R X C 9$ gene expression is early and transiently induced by exogenous treatment with SA, via an NPR1-independent pathway (Blanco et al. 2009). We confirmed these results by quantitative reverse transcription PCR (RT-qPCR), showing that a significant increase in GRXC9 transcript levels occurs after $2.5 \mathrm{~h}$ of SA treatment in both WT and npr 1-1 mutant plants (Online Resource 1). Considering that these results are in disagreement with a previous report that claims that GRXC9 expression induced by SA is dependent on NPR1 (Ndamukong et al. 2007), we used the npr 3-1 npr4-3 double mutant to further assess this point. NPR3 and NPR4 proteins are required to control NPR1 degradation (Fu et al. 2012). The npr3-1 npr4-3 mutant shows increased basal levels of NPR1 protein and, as a consequence, higher basal expression levels of NPR1-dependent $P R 1, P R 2$, and PR5 genes than the WT plants (Fu et al. 2012; Zhang et al. 2006). In the case of $G R X C 9$ expression, we detected an early and transient increase of transcript levels in the $n p r 3 \mathrm{npr} 4$ double mutants (Online Resource 1), while the basal levels remained unchanged when compared to WT or npr 1-1 plants (Online Resource 1, insert). This evidence confirms that GRXC 9 gene expression induced by SA treatment does not depend on NPR1 levels.

To further validate the SA-dependent and NPR1independent expression of GRXC 9 under physiological stress, we used UVB radiation as a stress condition since SA has been identified as a signaling molecule in this defense response (Surplus et al. 1998). To evaluate the GRXC9 gene expression dependence on SA, we used sid2-2 mutant plants that are deficient in SA biosynthesis (Wildermuth et al. 2001). Then, GRXC9 transcript levels were measured by RT-qPCR in WT, npr 1-1 and sid2-2 Arabidopsis plants exposed for 2.5 and $24 \mathrm{~h}$ to UVB light. Mean values from 3 to 6 replicates are shown in Fig. 1, while data from a representative replicate are shown in Online Resource 2. We detected significant increase in GRXC9 transcript levels after $24 \mathrm{~h}$ of stress exposure in WT and npr $1-1$ plants. This response was almost completely abolished in the sid2-2 mutant plants (Fig. 1a, Online Resource 2a). $P R-1$ gene expression after UVB treatment was evaluated as a control for the SA- and NPR1-dependent pathway (Fig. 1b, Online Resource 2b).

Concerning the basal levels of GRXC9 and PR-1 expression, we detected a reduction in nprl-1 and sid2-2 mutants compared to WT plants, but these differences were not statistically significant (Fig. 1a, b, Online Resource 1 and 2). Together, these results show that GRXC9 is an SA-dependent and NPR1-independent stress responsive gene. We used the GRXC9 gene as a a

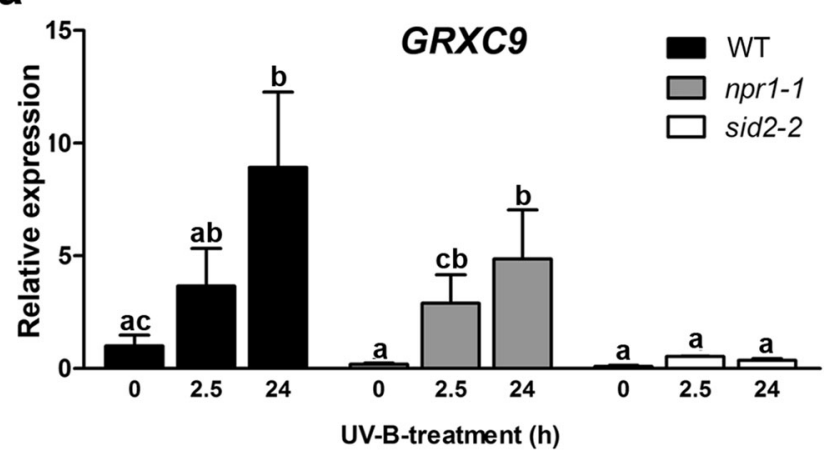

b

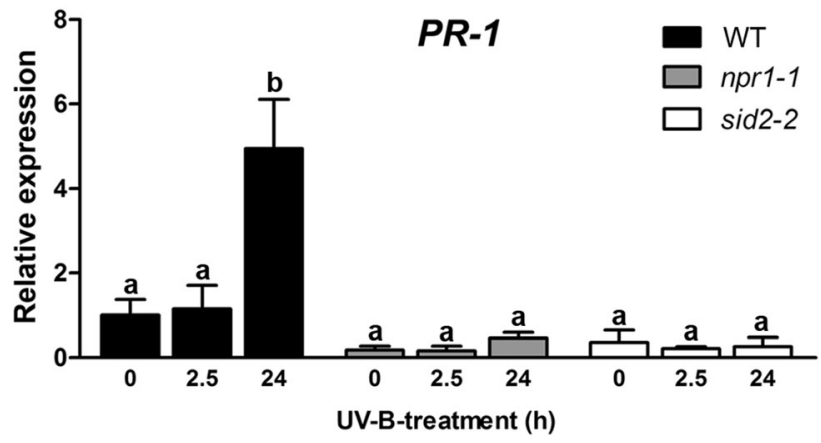

Fig. 1 GRXC9 expression levels in WT, sid2-2, and nprl-1 seedlings upon UVB chronic exposure. Expression levels of $G R X C 9$ (a) and $P R I$ (b) genes in 15-day-old seedlings from WT (black bars), nprl-1 (gray bars), and sid2-2 (white bars) backgrounds were exposed to UVB light. The transcript levels for each gene were quantified by RT-qPCR from samples collected after $0,2.5$, and $24 \mathrm{~h}$ of UVB exposure. The relative expression was calculated by normalizing the $G R X C 9$ and $P R 1$ transcript levels to that of the YLS8 gene and to the WT basal levels. Error bars represent the mean \pm standard error from 3 to 6 replicates. Data from a representative replicate is shown in Online Resource 2. Letters above the bars indicate significant differences based on unpaired $t$ test $(n \geq 3$, $p<0.05)$

model to inquire about the mechanism involved in this pathway.

Two as-1-Like Elements in the GRXC9 Promoter Are Required and Sufficient for SA-Mediated Transcriptional Activation

In silico analysis of the GRXC9 promoter sequence revealed the presence of several putative SA-responsive elements including two as-1-like elements, several $\mathrm{W}$ boxes, and isolated TGACG boxes (Online Resource 3). The proximal as-1-like element is located between -80 and $-99 \mathrm{bp}$, and the distal one is located between -114 and -133 bp upstream of the transcriptional start site (Fig. 2a and Online Resource 3). In order to evaluate whether these elements mediate the SA-dependent transcriptional activation of the gene, we generated Arabidopsis transgenic lines harboring different versions of the GRXC9 promoter fused to the GUS reporter gene. The constructs contained either the complete intergenic region 
a

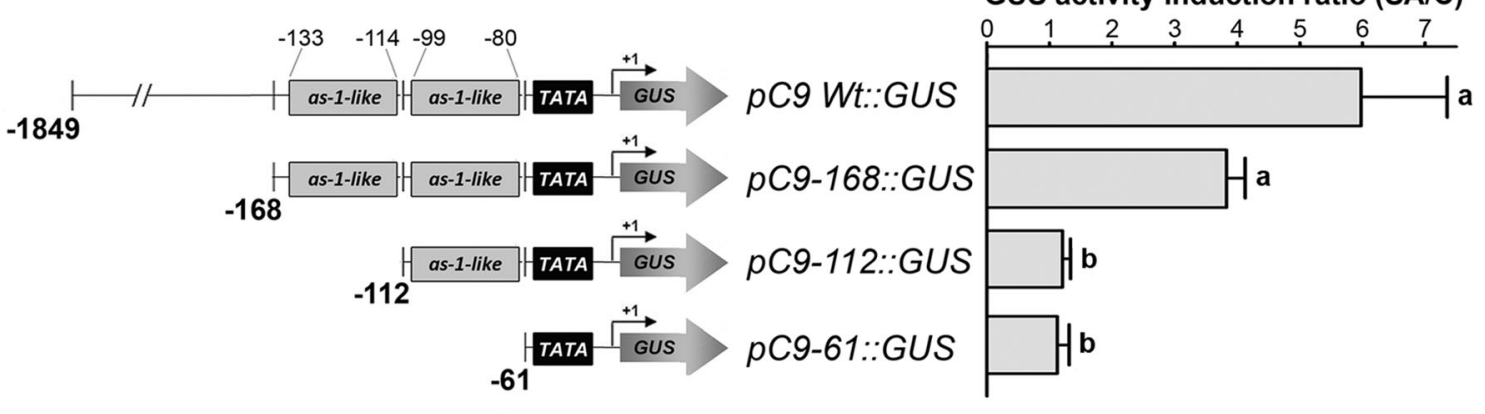

b

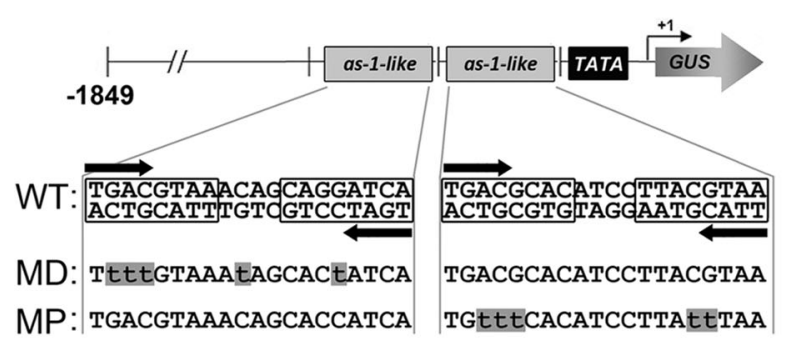

Fig. 2 GRXC9 promoter analysis by GUS reporter activity assays in Arabidopsis lines (a). The diagram represents the GRXC9 promoter constructs used to generate the GUS reporter lines. The numbers on the left side indicate the size of the promoter region cloned to drive GUS expression, and the numbers above the first construct indicate the position from the transcriptional start site of the as-1-like elements in the GRXC9 promoter. $p C 9$ WT::GUS complete intergenic region for GRXC9, $p C 9$ $168:: G U S$ promoter region containing the two as-1-like elements, $p C 9$ 112::GUS region containing the proximal as-1-like element, and $p C 9$ $61:: G U S$ sequence of the promoter region containing the putative TATA box. To quantify GUS activity induced by SA in the reporter lines, 6 to 13 homozygous lines per construct were selected. Fifteen-day-old seedlings from each line were treated with SA $0.5 \mathrm{mM}$ or $0.5 \times \mathrm{MS}$ as a control (C) for $2.5 \mathrm{~h}$. GUS activities were quantified in total protein extracts from each independent line and normalized with the total the amount of proteins (Online Resource 4). The ratio between SA treatment and its respective control was calculated, and the graph represents the average of GUS activity ratio obtained from the different lines. Error bars represent the standard error from three independent experiments. Letters indicate

$(-1,849$ to +26$)$, considered as the full GRXC9 promoter ( $p C 9$ $W T:: G U S)$, or truncated versions of this sequence that include the two as-1-like elements up to -168 bp ( $p C 9-168:: G U S$ ), only the proximal as-1-like element up to -112 bp ( $p C 9$ $112:: G U S$ ), or a minimal promoter up to -61 that includes the putative TATA box ( $p C 9-61:: G U S$ ) (Fig. 2a and Online Resource 3).

We treated seedlings (from six to 13 independent homozygous lines for each construct) with $0.5 \times \mathrm{MS}$ as control or with $0.5 \mathrm{mM} \mathrm{SA}$ for $2.5 \mathrm{~h}$. We then quantified the basal and SA-induced GUS activities in total protein extracts (Online Resource 4). The responsiveness to SA of each construct was represented as the mean value of the GUS activity induction ratio (SA-induced/basal GUS

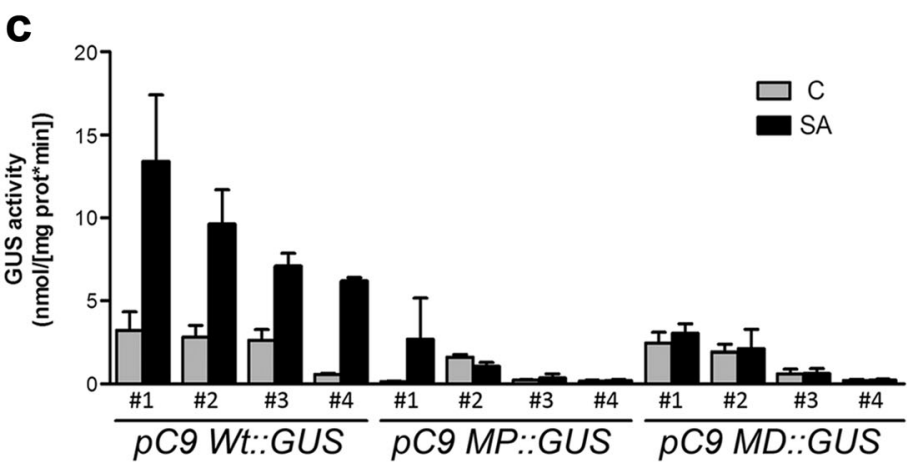

significant differences based on unpaired $t$ test $(p<0.05)$. b Schematic representation of genetic constructs containing site-directed mutations in the as-1-like elements, in the context of the full GRXC9 promoter sequence, and fused to GUS-coding region. $p C 9$ WT::GUS (WT in the scheme) was used as a template to mutate the TGACG boxes (indicated by black arrows) from the two as-1-like elements (highlighted in black boxes). The mutated base pairs in distal as-1-like element $(M D)$ and proximal as-1-like element $(M P)$ are indicated in lowercase and highlighted in gray boxes. $\mathbf{c}$ Four independent homozygous GUS reporter lines carrying the $p C 9$ WT::GUS and the mutated version in the proximal and distal $a s$ - 1 -like elements, $p C 9 M P:: G U S$ and $p C 9 M D:: G U S$, respectively (described in c), were used to quantify GUS activity. Fifteen-dayold seedlings were treated with SA $0.5 \mathrm{mM}$ (black bars) or $0.5 \times \mathrm{MS}$ (gray bars) as control for $2.5 \mathrm{~h}$, total proteins were prepared, and GUS activity was quantified and normalized with total protein concentration. The graph shows the mean value of three biological replicates for each line. Error bars represent the \pm standard error. Data from a representative replicate is shown in Online Resource 5

activities) (Fig. 2a). An average of sixfold increase in GUS activity after SA treatment was recorded in lines that contain the full promoter ( $p C 9$ WT::GUS), which indicates that GRXC9 gene expression is effectively activated by SA at the transcriptional level. Surprisingly, a very small promoter region up to -168 retains an important part of the SA responsiveness of the GRXC9 full promoter (Fig. 2a and Online Resource 4). This region contains both as-1-like elements, the most proximal TGACG box and the most proximal $\mathrm{W}$ box, while lacking all the rest of the putative SA-responsive elements (Online Resource 3 ). In contrast, lines expressing the $p C 9$ $112:: G U S$ and the $p C 9-61:: G U S$ constructs were completely insensitive to SA treatment (Fig. 2a and 
Online Resource 4), suggesting that the loss of the distal as-1-like element, and/or the proximal $\mathrm{W}$ and TGACG boxes, is enough to abolish SA-responsiveness.

To further evaluate the importance of the two as-l-like elements in the SA-responsiveness of the promoter, we generated genetic constructs containing the full GRXC9 promoter carrying point mutations in each as-1-like element (Fig. 2b). The nucleotides mutated in the as-l-like sequences were chosen considering the most conserved ones in the consensus as-1-like element detected in the cluster of genes induced by SA in a NPR1-independent manner (Blanco et al. 2009). Four independent Arabidopsis reporter lines were selected for each construct, either having mutations in the proximal ( $p C 9 M P::-$ $G U S$ ) or in the distal ( $p C 9 M D:: G U S)$ as-1-like elements (Fig. 2b). Seedlings from each line were treated with SA or $0.5 \times \mathrm{MS}$, and the GUS activity was quantified. As shown in Fig. 2c (see also Online Resource 5 for data from a representative replicate), lines that carry mutations in any of the two as- 1 elements no longer respond to SA treatment.

These results indicate that the increase in GRXC9 transcript levels in response to SA is mainly due to transcriptional activation of the gene mediated by this hormone and that the loss of any of the as-1-like elements is enough to abolish this activation. Both elements are functional, essential, and sufficient for SA responsiveness of the GRXC9 promoter.

SA-Induced GRXC9 Expression Is Abolished in tga2-1/tga5-1/tga6-1 Triple Mutants, While TGA2 and TGA3 Are Constitutively Bound to the GRXC9 Promoter In Vivo

It has been reported that $G R X C 9$ induction by SA treatment is abolished in the TGA class II triple mutant (tga2-1/tga5-1/ tga6-1) (Blanco et al. 2009; Ndamukong et al. 2007). Nevertheless, the possible participation of other members of the TGA family proteins, as well as the direct binding of TGA factors to the GRXC9 promoter, has not been addressed. With this purpose in mind, we first analyzed the SA-induced expression of GRXC 9 by RT-qPCR in different $\operatorname{tg} a$ mutant backgrounds (Fig. 3). Considering that TGAs belonging to class I (TGA1 and TGA4) and class II (TGA2, TGA5, and TGA6) show different degrees of redundancy (Zhang et al. 2003; Kesarwani et al. 2007), we used the double and triple mutant, respectively. The redundancy of TGA class III (TGA3 and TGA7) has not been demonstrated, and thus we analyzed the single mutants for each gene (Kesarwani et al. 2007). We correlated the expression data with in vivo binding assays of TGA factors to the GRXC9 promoter after SA treatment using chromatin immunoprecipitation (ChIP) assays (Fig. 4). ChIPqPCR assays were performed in WT plants treated with SA or $0.5 \times$ MS as control, using primers that amplify a 290 -bp fragment $(-212$ to +78 region) that includes the basal promoter and the as-1-like elements (Fig. 4a). Antibodies that specifically recognize TGA1, TGA2, and TGA3, raised against the divergent $\mathrm{N}$ terminal regions, were used (Lam and Lam 1995).

In the double mutant of class I TGAs (tga1-1/tga4-1), GRXC 9 expression was early and transiently activated reaching its peak $2.5 \mathrm{~h}$ after SA treatment, as in WT plants (Fig. 3). Accordingly, the in vivo binding of TGA1 to the GRXC9 promoter, evaluated by ChIP-qPCR, was not detected either under control conditions or after $2.5 \mathrm{~h}$ of SA treatment (Fig. 4b). These results indicate that class I TGAs are not involved in GRXC9 induction.

In contrast, GRXC9 induction by SA was significantly reduced in the triple mutant of TGA class II (tga2-1/tga5-1/ tga6-1), compared to WT plants (Fig. 3), although a slight increase of the transcript after $2.5 \mathrm{~h}$ of SA was observed. On the other hand, the induction level by SA was $33.4 \%$ reduced in the tga3-1 mutant compared to WT plants, albeit this difference was not statistically significant (Fig. 3). To better evaluate the importance of TGA3 in GRXC9 expression, we also assayed the quadruple tga2-1/tga3-1/tga5-1/tga6-1 mutant background. Although the lack of TGA class II had a striking negative effect on SA-induced GRXC9 transcription, the slight increase in messenger RNA (mRNA) levels after $2.5 \mathrm{~h}$ of SA treatment seen in the triple mutant is no longer observed in the quadruple mutant (Fig. 3). These results support that TGA class II, and to a lesser extent TGA3, is involved in GRXC9 induction by SA. Interestingly, mutations in TGA class II and TGA3 factors also have an effect on the basal levels of GRXC9 expression (Fig. 3, insert). Compared to WT plants, basal GRXC9 transcript levels are reduced in the single tga3-1 and in the triple tga2-1/tga5-1/tga6-1 mutants, and this difference is higher and only statistically significant in the quadruple tga2-1/tga3-1/tga5-1/tga6-1 mutant (Fig. 3 insert). Supporting these expression results, ChIP-qPCR assays show that TGA2 and TGA3 are constitutively bound to the GRXC9 promoter, either in the presence or in the absence of SA stimulus (Fig. 4c, d).

Surprisingly, the lack of TGA7 produces a significant increase in GRXC9 induction by SA (Fig. 3), suggesting that TGA7 can play a negative role in this control mechanism. We did not detect involvement of TGA factors in repressing $G R X C 9$ expression under basal conditions (Fig. 3, insert), in contrast to what was previously reported for $P R-1$ expression (Kesarwani et al. 2007).

Together, these results indicate that constitutive binding of the TGA2 factor to the GRXC9 promoter is essential for transcriptional activation mediated by SA. Even though TGA3 is also constitutively bound, its role is more important in the basal than in the SA-induced GRXC9 expression.

Considering that the constitutive binding of TGA2 and TGA3 to the GRXC9 promoter detected in vivo does not correlate with the constitutive expression of the gene, we propose that these TGA factors could bind either as homo or 


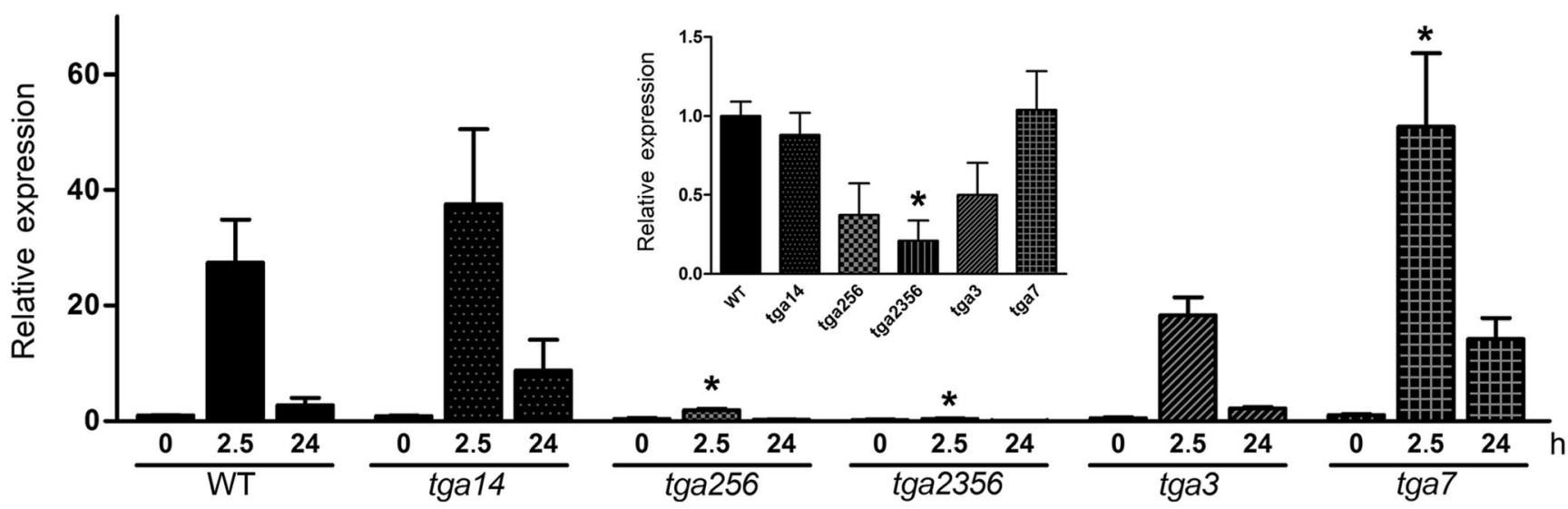

Fig. 3 GRXC9 gene expression in tga mutant backgrounds. Expression analysis of the GRXC9 gene was evaluated by RT-qPCR in 15-day-old seedlings of WT, tga1-1tga4-1 (tga14), tga3-1 (tga3), tga7-1 (tga7), tga2-1tga5-1tga6-1 (tga250), and tga2-1tga3-1tga5-1tga6-1 (tga2356) genotypes, under basal conditions (insert) and after treatment with SA $0.5 \mathrm{mM}$ or $0.5 \times \mathrm{MS}$ as a control for 2.5 and $24 \mathrm{~h}$. The GRXC9 relative expression was calculated by normalizing the expression level of $G R X C 9$ with the expression level of the housekeeping gene Clathrin adaptor complex subunit and with the WT basal condition. Error bars represent the \pm standard error from three biological replicates $\left({ }^{*} p<0.05\right.$, compared to the WT genotype in a two-way ANOVA and Bonferroni post test) heterodimers, without being directly able to transactivate transcription. In order to evaluate the potential homodimerization and heterodimerization ability of TGA class II and TGA3 factors, as well as their transactivation activity, we performed yeast one and two hybrid assays. For this purpose, we cloned the CDS of TGA factors in frame with the DNA-binding domain (BD) or the activation domain (AD) of the yeast Gal4 factor. Interactions between TGA factors were evaluated in yeast by qualitative assays of the $\beta$-galactosidase reporter gene, whose expression is controlled by four copies of the Gal4-responsive element. The transactivation ability of the TGA factors was evaluated in assays using the TGA factors fused to the BD-Gal4 and the empty pDEST22 vector. Our results indicate that TGA2, TGA3, TGA5, and TGA6 cannot transactivate the $\beta$-galactosidase gene in a yeast system, reflected by the null activity of the reporter enzyme (Online Resource 6, first lane). Furthermore, the two-hybrid assays show that TGA class II and TGA3 factors are able to homodimerize and also heterodimerize among them (Online Resource 6). The interaction between NPR1 and TGA2 proteins was used as a positive control in these assays (Fan and Dong 2002).

These results support the idea that TGA2 and TGA3 bind to the GRXC9 promoter, most probably through the SAresponsive as-1-like elements, both as homodimers or heterodimers, without acting directly in transactivation.

SA Induces the Transient Recruitment of RNA Polymerase II to the GRXC9 Promoter by a TGA Class II-Dependent Mechanism

We evaluated whether, independently of the constitutive binding of TGA 2 and TGA 3 to the $G R X C 9$ promoter, the transient increase in GRXC9 transcript levels correlates with a transient recruitment of Pol II to the GRXC9 promoter, induced by SA. In order to test this, Arabidopsis seedlings were treated with $0.5 \mathrm{mM}$ SA or $0.5 \times$ MS as a control, and ChIP assays were performed at different times. We used antibodies that recognize the N-terminal domain of Pol II from Arabidopsis and the set of primers previously described (Fig. 4a). Interestingly, we found a good correlation between the increment in GRXC9 mRNA levels (Fig. 3, Online Resource 1a) and the recruitment of Pol II to the GRXC9 promoter triggered by SA (Fig. 5a). Similarly, the recruitment of Pol II, as well as GRXC9 expression, was abolished in the tga2-1/tga5-1/tga61 triple mutant (Figs. 5b and 3).

Taken together, these results indicate that SA triggers the transient recruitment of Pol II to the basal GRXC9 promoter, which explains the transient increase in GRXC9 transcript levels triggered by SA. On the other hand, the fact that the increase in GRXC9 transcript levels and the Pol II recruitment are impaired in the tga2-1/tga5-1/tga6-1 triple mutant suggests that the constitutive binding of TGA factors is required for differential Pol II recruitment to the promoter.

Overexpression of GRXC9 Downregulates the Expression of its Endogenous Gene

It has been shown that TGA2 and GRXC9 are able to interact in vivo and that this interaction may have a role in controlling the expression of genes involved in the defense response triggered by jasmonic acid (Ndamukong et al. 2007). However, the significance of this interaction in the SA response has not been addressed. Our results indicate that TGA2 is a key factor in the transcriptional induction of GRXC9, and thus we evaluated whether the overexpression of $G R X C 9$ has an effect in its own transient SA-dependent transcriptional induction. 
a

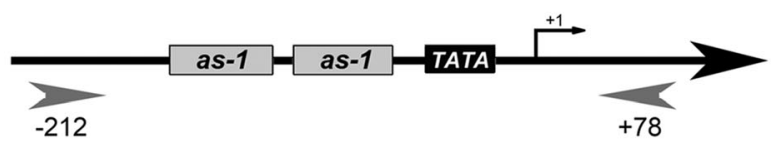

b

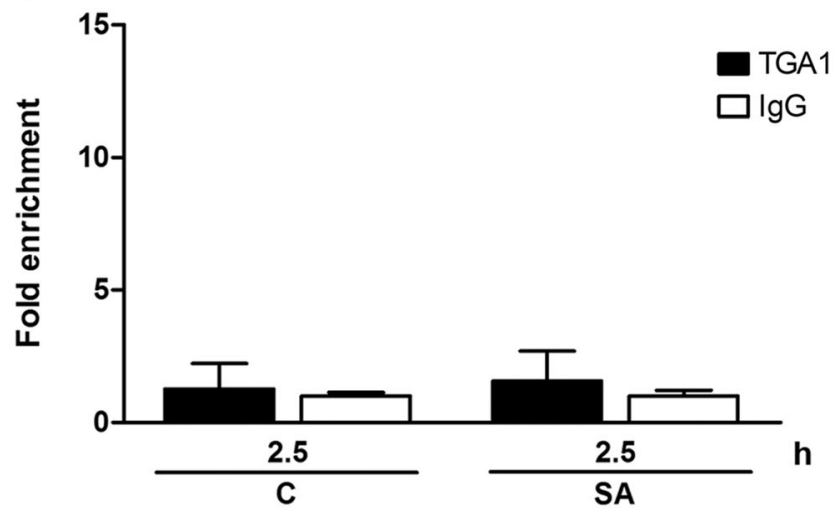

C

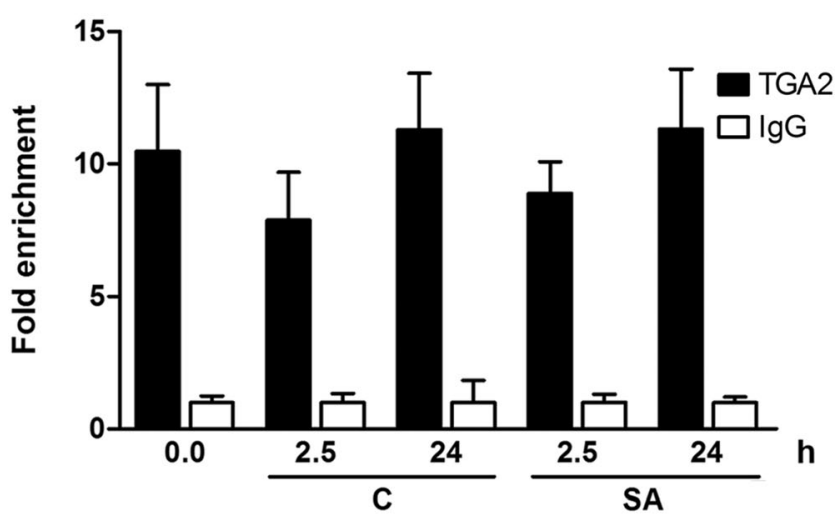

d

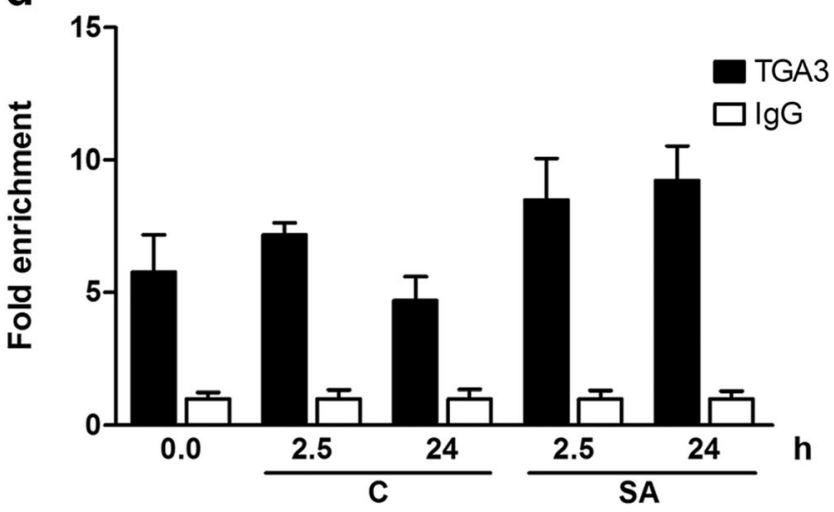

We produced WT transgenic lines harboring the CaMV $35 \mathrm{~S}$ promoter controlling the expression of the GRXC9-coding region fused to the immunological cMyc tag. We chose two homozygous lines (L3 and L7) with high constitutive expression levels of GRXC9 (Fig. 6a). We then evaluated the
Fig. 4 Analysis of TGAs binding to as-1-like elements of the GRXC9 promoter by ChIP-qPCR assays. a Diagram of the GRXC9 promoter region amplified in the ChIP-qPCR assays. The arrowheads indicate the location of the primers used to quantify the DNA of the GRXC9 promoter bound to TGAs by qPCR. Fifteen-day-old plants treated with $0.5 \mathrm{mM} \mathrm{SA}(S A)$ or $0.5 \times \mathrm{MS}$ as control $(C)$ for 2.5 and $24 \mathrm{~h}$ were used to perform ChIP-qPCR assays. Antibodies raised against TGA1 (b), TGA2 (c), and TGA3 (d) transcription factors (in black bars) or IgG as a control (white bars) were used for the ChIP assays. qPCR analyses to quantify the DNA recovered from the ChIP were performed using the primers described in a. The values for the immunoprecipitated DNA samples are expressed as fold enrichment with the specific antibody over a nonspecific immunoprecipitation condition (IgG). Error bars represent \pm standard error of three biological replicates

levels of the endogenous $G R X C 9$ transcript by RT-qPCR in WT and overexpressor lines treated with SA or $0.5 \times \mathrm{MS}$ as control for $2.5 \mathrm{~h}$. As shown in Fig. 6b, SA induction of the endogenous GRXC9 gene was significantly reduced in both overexpressor lines to less than $50 \%$ of the SA induction

a

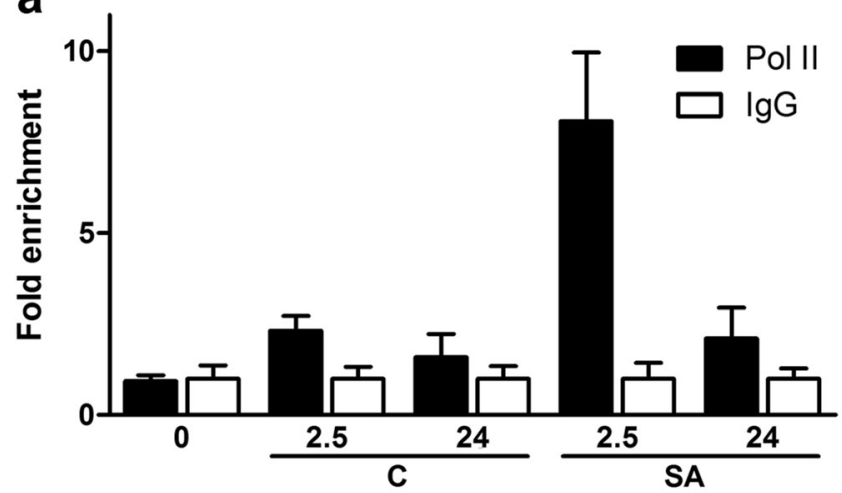

b

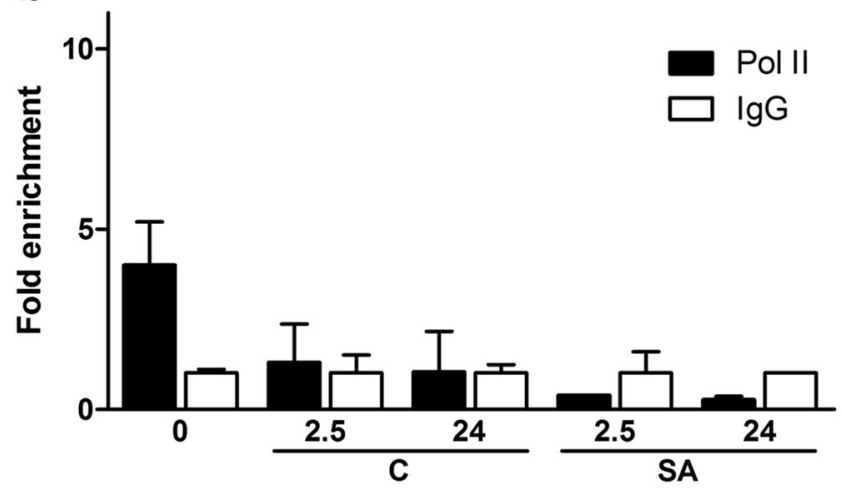

Fig. 5 Recruitment of the RNA Pol II to the GRXC9 promoter region by ChIP-qPCR assays. WT (a) and tga2-1 tga 5-1 tga 6-1 (b) plants treated with $0.5 \mathrm{mM} \mathrm{SA}(S A)$ or $0.5 \times \mathrm{MS}$ as control $(C)$ for $0,2.5$, and $24 \mathrm{~h}$ were used to perform ChIP-qPCR assays. The ChIP assays were performed with a polyclonal antibody raised against the Pol II (black bars) or with a purified IgG (white bars) as a control. The qPCR analyses to quantify the DNA recovered from the ChIP were performed using the primers described in Fig. 4a. The values for the immunoprecipitated DNA samples were expressed as fold enrichment with the specific antibody over a nonspecific immunoprecipitation condition (IgG). Error bars represent \pm standard error of three biological replicates 
observed in WT plants. Although basal levels of GRXC9 expression are reduced in both overexpressor lines compared to WT, these differences were not statistically significant (Fig. 6b). As a control, we show that overexpression of GRXC9 does not affect basal or SA-induced PR-1 gene expression (Online Resource 7). These results suggest that GRXC9 negatively regulates the expression of its own gene.

To further investigate the role of GRXC9 in the regulation of its own gene, we used ChIP-qPCR assays in the overexpressor lines to evaluate whether the GRXC9-Myc protein is associated with the TGA2/TGA3 complex bound to the $a s$ - 1 -like elements in the GRXC9 promoter. Interestingly, we detected that GRXC9-Myc protein effectively forms part of the protein complex bound to the promoter (Fig. 6c), strongly suggesting that $G R X C 9$ regulates its own gene expression through binding to TGA factors while they are bound to the DNA.

\section{Discussion}

In this study, we explore the mechanism of control of gene expression via an SA-dependent and NPR1independent pathway in Arabidopsis, using GRXC9 as a model gene. First, we showed evidence for the induction of GRXC9 expression through this pathway in response to UVB stress, validating its activation in the context of a defense response to stress (Fig. 1a). By assaying in planta GRXC9-GUS reporter activity (Fig. 2a) and in vivo binding of Pol II to the GRXC9 promoter (Fig. 5a), we showed that the control of GRXC9 gene expression by SA is exerted at the initiation of transcription. Accordingly, we established that TGA class II factors (Figs. 3 and $5 \mathrm{~b}$ ), as well as the two as-1-like elements located in the GRXC9 proximal promoter (Fig. 2c), are essential for the induction of GRXC9 expression by SA. The constitutive binding of TGA2 and TGA3 factors to the GRXC9 promoter, as detected by in vivo ChIP assays (Fig. 4), indicates that the inducing effect of SA is not due to an increase in binding of TGA factors to the as-1-like elements. TGA class II and TGA3 factors have the capacity to interact with each other, as detected in yeast by two-hybrid assays (Online Resource 6), suggesting that TGA2 and TGA3 can bind to the GRXC9 promoter as homodimers or heterodimers. Furthermore, TGA class II and TGA3 factors did not show transactivation capacity in yeast one-hybrid assays (Online Resource 6). Therefore, even though TGA class II factors are essential for recruiting Pol II to the GRXC9 promoter (Fig. 5b), additional coregulators are required for transactivation. Finally, we showed that overexpressed GRXC9-Myc protein binds to the TGA-
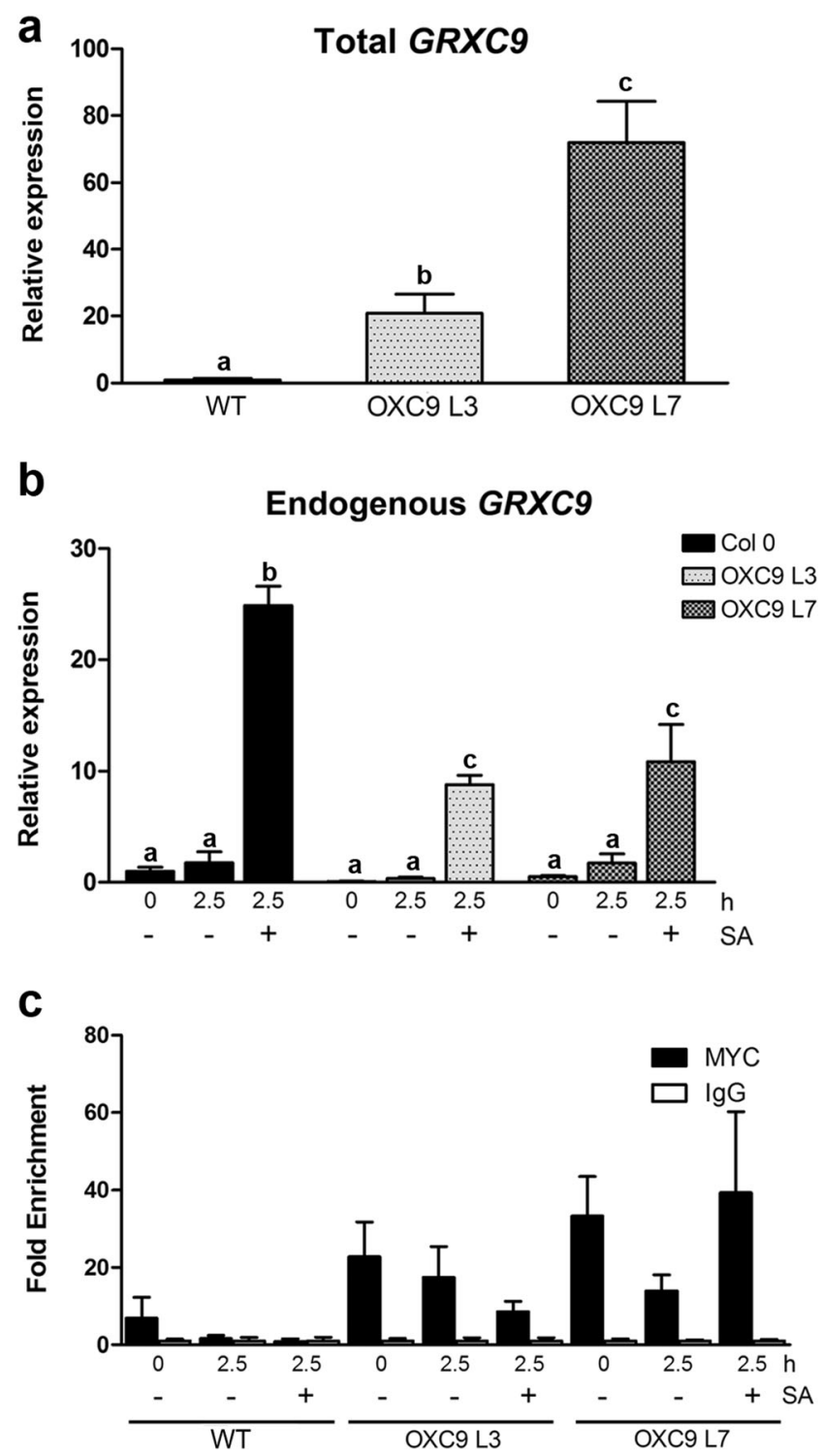

Fig. 6 Effect of GRXC9 overexpression on GRXC9 gene expression and on binding to the GRXC9 promoter. The levels of total (a) and endogenous (b) GRXC9 transcripts were detected by RT-qPCR in 15-day-old seedlings of WT and GRXC9 OE lines (L3 and L7) treated with SA $0.5 \mathrm{mM}$ or $0.5 \times \mathrm{MS}$ as a control for $2.5 \mathrm{~h}$. GRXC9 relative expression was calculated by normalizing the expression level of GRXC9 with the expression level of the housekeeping gene YLSS and to the WT basal condition. Error bars represent the \pm standard error. Letters above the bars indicate significant differences based on unpaired $t$ test $(n=3$, $p<0.05)$. The binding of GRXC9-Myc protein to the endogenous promoter of $G R X C 9$ was evaluated by ChIP-qPCR (c). WT plants and the two overexpressor lines (OXC9 L3 and OXC9 L7) were evaluated in the conditions mentioned above. The immunoprecipitation was performed with commercial antibodies raised against the MYC-tag (black bars) and a nonspecific IgG (white bars) as control. The qPCR analyses to quantify the DNA recovered from the ChIP were performed using the primers described in Fig. 4a. The values for the immunoprecipitated DNA samples were expressed as fold enrichment of the specific antibody over a nonspecific immunoprecipitation condition ( $\mathrm{IgG})$. Error bars represent \pm standard error of three biological replicates 
containing complex at the GRXC9 promoter and inhibits SA-mediated induction of the gene (Fig. 6). This result, together with previous evidence showing that the GRXC9 protein can interact with TGA2 in the nucleus (Ndamukong et al. 2007), suggests that GRXC9 negatively controls its own gene through binding to TGA factors while they are bound to the DNA, turning off gene expression.

Role of the SA-Dependent and NPR1-Independent Pathway in the Stress Defense Response

The existence of an SA-dependent and NPR1-independent pathway for the expression of genes with a putative antioxidant and/or detoxifying roles in defense, such as GRXS, GSTS, and $U G T s$ (coding for UDP-glucosyl transferases), has been reported by our group and by others (Lieberherr et al. 2003; Blanco et al. 2005, 2009; Uquillas et al. 2004; LangloisMeurinne et al. 2005; Fode et al. 2008). The induction of two GST (Lieberherr et al. 2003) and three UGT genes (Langlois-Meurinne et al. 2005), through an SA-dependent and NPR1-independent mechanism, was reported in Arabidopsis plants inoculated with avirulent strains of Pseudomonas syringae pv. tomato (Pst). Here, we validate the activation of the GRXC9 gene by this pathway under an abiotic stress condition such as UVB radiation that, like the immune reaction induced by avirulent $P s t$ strains, triggers an SA-mediated defense response (Surplus et al. 1998).

On the other hand, members of GST and UGT gene families have also been found to be responsive to treatments with oxilipins (including JA) and xenobiotic chemicals like 2,4-D, in the context of the chemical detoxification process. Based on the overlap of some GST and UGT (early NPR1-independent SAIG (Blanco et al. 2009) that are also responsive to oxilipins/ xenobiotics (Fode et al. 2008; Baerson et al. 2005; Mueller et al. 2008), as well as on the involvement of common TGA factors and as-1-like elements in their transcriptional control (as discussed in the next section), it was assumed that exogenous treatments with SA unspecifically induced the chemical detoxification process (Fode et al. 2008; Gatz 2012). Results shown in this work for GRXC9 and in other works for the GSTF2, GSTF6, UGT73B3, UGT73B5, and UGT73D1 genes (Lieberherr et al. 2003; Langlois-Meurinne et al. 2005) clearly argue against this idea, indicating that these antioxidant/detoxifying genes are activated by an endogenous stress-driven and SA-mediated pathway, which is distinct from the NPR1-dependent pathway that activates defense genes such as $P R-1$. The rapid and transient expression of genes with antioxidant and detoxifying roles could be important to restrict the oxidative burst produced in the infected/damaged tissues, avoiding the oxidative damage of systemic tissues.

Mechanistic Aspects of the Transcriptional Control of GRXC9 Expression via an SA-Dependent and NPR1-Independent Pathway. Involvement of TGA Class II Factors and $a s$-1-Like Promoter Elements

Evidence provided in this paper further supports the idea that, even though as-1-like and isolated TGACG boxes bind the same class of TGA factors, they are functionally different. These factors respond to different pathways to control the expression of distinct groups of genes that are activated at different times during the defense response, using different mechanism for promoter recognition and activation.

In Arabidopsis, as-1-like elements are overrepresented in promoters of genes that code for enzymes with antioxidant or detoxifying activity that is responsive to exogenous application of SA, xenobiotics, and oxilipins (Blanco et al. 2009; Fode et al. 2008; Köster et al. 2012). Functional requirement for $a s$-1-like elements has been previously reported for only a couple of these Arabidopsis genes: GST6 coding for a GST inducible by xenobiotics, $\mathrm{H}_{2} \mathrm{O}_{2}$, and SA (Chen and Singh 1999) and CYP81D11 coding for a cytochrome P450 inducible by xenobiotics (Köster et al. 2012). The functional analysis of the as-1-like elements from the GRXC9 promoter described in this work represents the first functional promoter analysis performed in an early SA-dependent and NPR1independent gene activated under an abiotic stress.

The GRXC9 gene has two contiguous as-1-like elements in its promoter sequence (Fig. $2 \mathrm{~b}$ and Online Resource 3). In both cases, the second TGACG box is less conserved than the first one, as previously described for other $a s$ - 1 -like elements (Ellis et al. 1993). The functional analysis of the GRXC9 gene promoter clearly indicates that both as-1-like elements are essential for SA-mediated expression of the gene (Fig. 2). Interestingly, the all or none effect of mutating any as-1-like element, instead of additive or synergistic effects, indicates that both elements must work together in the formation of transcriptional complexes.

In contrast, isolated TGACG boxes are enriched in promoters of SAIGs by an NPR1-dependent pathway (Maleck et al. 2000). Functional requirement of a TGACG box for SAmediated expression was demonstrated for $P R-1$ and NIMIN1 promoters, which are known to be induced by SA via an NPR1-dependent mechanism (Lebel et al. 1998; Fonseca et al. 2010). In the case of the $P R-1$ gene, isolated TGACG boxes control its transcriptional activation by SA and its repression under basal conditions (Lebel et al. 1998).

Interestingly, this work shows that common TGA factors (TGA class II and TGA3) recognize as-1-like elements and TGACG boxes, being therefore involved in different transcriptional control processes. In Arabidopsis, TGA class II 
factors have been reported to be essential in several processes: the basal repression and the SA-mediated and NPR1dependent induction of plant TGACG box-containing genes, such as PR1 gene (Rochon et al. 2006; Kesarwani et al. 2007; Zhang et al. 2003), the induction of as-1-like-containing plant genes belonging to the chemical detoxification process, in response to treatments with xenobiotics and oxilipins (including JA) (Fode et al. 2008; Mueller et al. 2008; Stotz et al. 2013), the induction of JA/ethylene-inducible genes like PDF1.2 and its negative modulation by SA (Ndamukong et al. 2007; Zander et al. 2010), and the SA-mediated induction of early and NPR1-independent SAIGs (Blanco et al. 2009), the last one supported by the results of this work.

One interesting conclusion of this work is that TGA2 is involved in different signaling pathways that operate at different times in the response to stress (UVB in this case). One of these pathways leads to the expression of early SAdependent and NPR1-independent genes, such as GRXC9; the other pathway leads to the expression of late SA- and NPR1-dependent genes, such as PR1 (Fig. 1). Furthermore, in the case of GRXC9, TGA2 is bound to the promoter during all the phases of its expression profile (Fig. 4), being essential for the transient increase in transcript levels (Fig. 3) and recruitment of the Pol II (Fig. 5). The question is that how is the activity of TGA factors that are involved in different mechanisms of transcriptional control and that act at different times after stress controlled?

Results showed in this work prompt us to propose a model (Fig. 7) to explain how SA controls the transcription process of $G R X C 9$ in the context of the defense response to stress. According to our model, TGA2 and TGA3 (forming homodimers or heterodimers, T2/3) are constitutively bound to the two as-1-like elements of the GRXC9 promoter. Under basal conditions, we propose that an inactive form of a coregulator complex $\left(\mathrm{Co}-\mathrm{R}_{\mathrm{I}}\right)$ is bound to the TGA2-3/as-1like complex, forming a transcriptionally inactive complex. Upon a stress condition, SA levels increase producing the activation of the coregulator complex (switch from Co- $\mathrm{R}_{\mathrm{I}}$ to Co- $\mathrm{R}_{\mathrm{A}}$ ). According to our results, Co- $\mathrm{R}_{\mathrm{A}}$ must provide the transactivation activity for recruitment of the Pol II basal machinery (Pol II complex) to initiate transcription. According to our results with the GRXC9 overexpressor lines (Fig. 6), we propose that the $G R X C 9$ protein is involved in turning off the SA-mediated activation of its own gene through a direct interaction with the TGA2-3/as-1-like complex. So, once $G R X C 9$ gene expression is induced, the GRXC9 protein produced and translocated to the nucleus could bind the TGA2-3/ as-1-like complex, as indicated by Ndamukong et al. (2007). We propose that GRXC9 bound to the complex promotes the inactivation of the coregulator complex $\left(\mathrm{Co}-\mathrm{R}_{\mathrm{A}}\right.$ to $\left.\mathrm{Co}-\mathrm{R}_{\mathrm{I}}\right)$, switching from a transcriptionally active to a transcriptionally inactive complex. GRXC9 expression is turned off because Co- $\mathrm{R}_{\mathrm{I}}$ does not have the ability to recruit Pol II basal machinery. This mechanism would allow a rapid transcriptional response to stress signals, through transient changes in the activity of a coregulator complex bound to the TGA2TGA3/as-1-like platform complex preformed at the GRXC9 promoter.

Results indicating that GRXC9 and TGA2 interact in the nucleus and that GRXC9 overexpression reduces the expression of the 2,4-D-inducible CaMVas-1::GUS transgene and the JA-inducible PDF1.2 gene (Ndamukong et al. 2007) support the idea that GRXC9 could play a more general role in controlling the expression of TGA class II-target genes. Interestingly, the binding of other CC-type GRX (ROXY1 and ROXY2) to TGA9/10 factors and their role in anthers development (Murmu et al. 2010) supports a role for CC-type $G R X S$ in the control of gene expression. Considering that ROXY1 must be expressed in the nucleus to complement roxy1 mutant and that GRXC9 can also complement the roxy 1 mutant ( $\mathrm{Li}$ et al. 2009), it can be inferred that nuclear $G R X C 9$ is required to exert its activity. Our results indicating that $G R X C 9$ binds to the TGA2-3/as-1-like complex support this idea.

One of the key questions raised by this model is what is the nature of the proteins that form the coregulator complex, either in its active $\left(\mathrm{Co}-\mathrm{R}_{\mathrm{A}}\right)$ or inactive $\left(\mathrm{Co}-\mathrm{R}_{\mathrm{I}}\right)$ forms. The existence of a corepressor complex that binds the TGA2-3/as1-like complex under basal conditions (Fig. 7) was previously proposed for the 35SCaMV as- 1 in tobacco (Johnson et al. 2001; Butterbrodt et al. 2006). In the case of GRXC9, previous evidence showing that treatment with the protein inhibitor cycloheximide highly increases the basal and SA-induced levels of GRXC9 transcripts suggests the existence of a repressor with a high turnover rate (Blanco et al. 2009). More recently, a subunit of the mediator complex (MED18) was found to be essential for suppression of GRXC9 as well as GRXS13 and TRX-h5 expression in the absence of stress, suggesting that this subunit forms part of the Co- $\mathrm{R}_{\mathrm{I}}$ complex (Lai et al. 2014). On the other hand, we show here evidence that although TGA2 and TGA3 are basally bound to the GRXC9 promoter, their binding is not required for turning off the gene in the absence of stress. In fact, knockout mutants for TGA class II and TGA3 factors do not show increased basal levels of GRXC9 transcripts (Fig. 3). Together, this evidence indicates that even though TGA2/TGA3 and Co- $\mathrm{R}_{\mathrm{I}}$ (probably containing MED18) form part of the basal inactive complex, the presence of MED18 but not of TGA2/TGA3 factors is essential to repress $G R X C 9$ transcription.

Concerning proteins with coactivator function that could be part of the Co- $\mathrm{R}_{\mathrm{A}}$ complex, we discard NPR1 and SCL14 proteins. In fact, the induction of GRXC9 by SA is not only independent of the NPR1 protein ((Blanco et al. 2009) and Online Resource 1) but also independent of the SCL14 protein (Fode et al. 2008), which was previously identified as an interactor of TGA2 factor essential for the expression of a group of as-1-like-containing genes. Previously, a Dof protein 


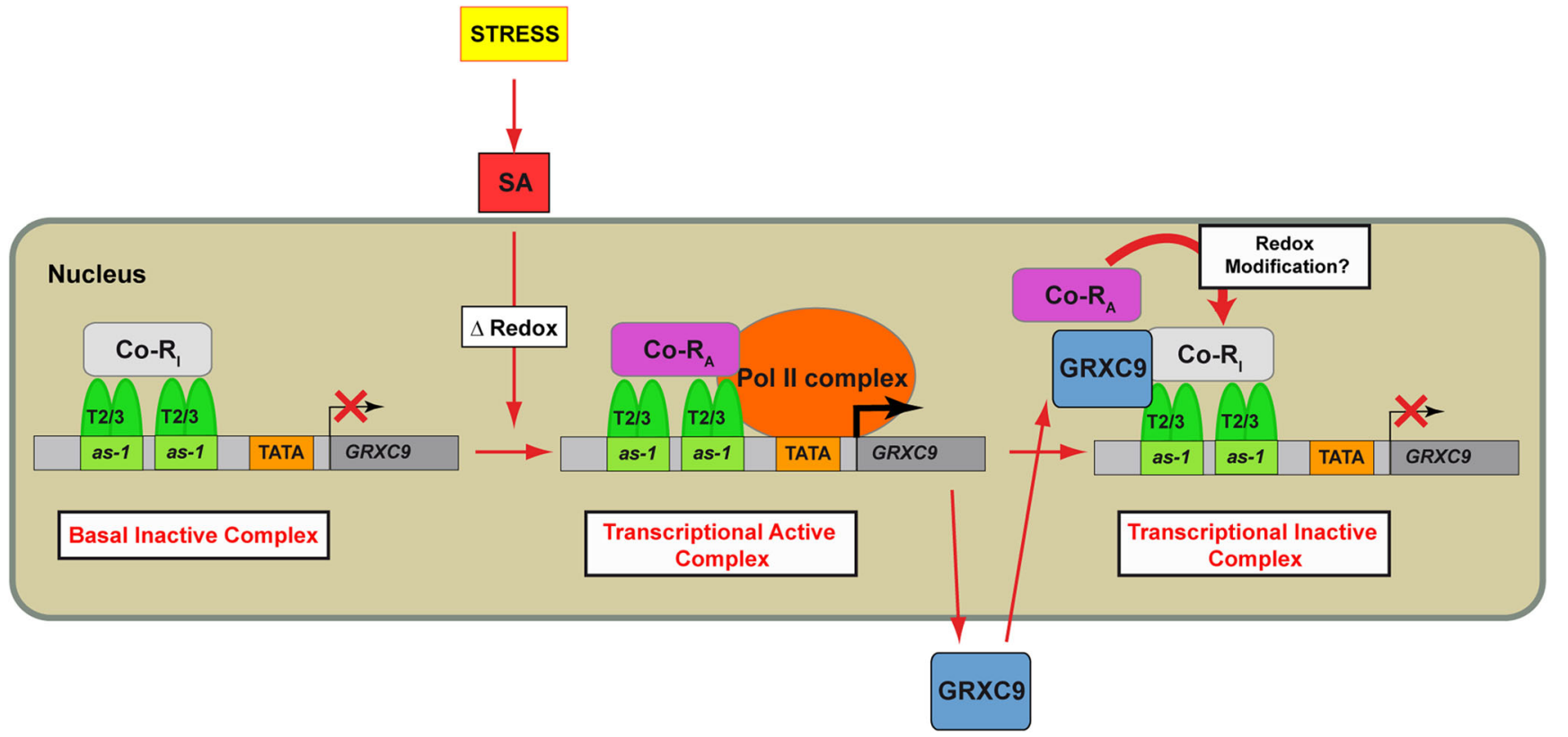

Fig. 7 Mechanistic model for the transcriptional control of GRXC9 expression by stress, via an SA-dependent and NPR1-independent pathway in Arabidopsis. Homodimers or heterodimers of TGA2 and TGA3 (T2/3) are constitutively bound to the two as-1-like elements of the GRXC9 promoter, acting as a platform for the formation of transcriptionally inactive and active complexes. Under basal conditions, an inactive form of a coregulator $\left(\mathrm{Co}-\mathrm{R}_{\mathrm{I}}\right)$ is bound to the TGA2-3/as-1-like complex forming a basal complex that impairs recruitment of the Pol II to the GRXC9 promoter. Upon stress, SA is rapidly accumulated promoting the activation of the coregulator complex (switch from Co- $\mathrm{R}_{\mathrm{I}}$ to $\mathrm{Co}-\mathrm{R}_{\mathrm{A}}$ ) that

named OBP1 was found to interact with TGA4 and TGA5 to enhance binding to the as- 1 element (Zhang et al. 1995); whether this kind of protein forms part of the Co- $\mathrm{R}_{\mathrm{A}}$ complex remains to be elucidated. Therefore, further efforts are required for the identification of the protein(s) that form part of the Co- $\mathrm{R}_{\mathrm{A}}$ complex that binds to the TGA2-3/as-1-like complex in GRXC9 promoter.

Another interesting question raised by this model is what is the mechanism by which SA promotes the activation of the coregulator complex (switch from Co- $\mathrm{R}_{\mathrm{I}}$ to $\mathrm{Co}-\mathrm{R}_{\mathrm{A}}$ ), as well as how GRXC9 can promote the inactivation of the coregulator complex (switch from Co- $\mathrm{R}_{\mathrm{A}}$ to $\mathrm{Co}-\mathrm{R}_{\mathrm{I}}$ ). We speculate in our model that a redox change promoted by $\mathrm{SA}$ accumulation can be responsible for the activation of the coregulator complex. This idea is supported by evidence indicating that SA promotes a biphasic change in the GSH/GSSG ratio, first an oxidative phase characterized by a decrease in GSH/GSSG ratio and then a reductive phase characterized by increase in GSH/GSSG ratio (Mou et al. 2003; Mateo et al. 2006). With respect to the mechanism of inactivation of the coregulator complex, we speculate that GRXC9, through its oxidoreductase activity, can catalyze the reduction of a protein that forms part of the coregulator complex, producing its binds to the TGA2-3/as-1-like complex, allowing the formation of a transcriptionally active complex that recruits the Pol II basal machinery (Pol II complex) to the GRXC9 basal promoter. Transcription of GRXC9 leads to the accumulation of the GRXC9 protein in the nucleus where it binds to the TGA2-3/as-1-like complex producing the inactivation of the coregulator complex (switch from $\mathrm{Co}-\mathrm{R}_{\mathrm{A}}$ to $\mathrm{Co}-\mathrm{R}_{\mathrm{I}}$ ) and therefore turning off $G R X C 9$ transcription. We speculate that the switch from Co- $\mathrm{R}_{\mathrm{I}}$ to Co$\mathrm{R}_{\mathrm{A}}$ promoted by $\mathrm{SA}$ is produced by the oxidative modification of one of the proteins involved in the promoter complex, while the switch from Co$\mathrm{R}_{\mathrm{A}}$ to Co- $\mathrm{R}_{\mathrm{I}}$ is produced by the protein's reduction catalyzed by GRXC 9

inactivation. GRXC9 could be a key piece in the redox control of the expression of genes controlled by TGA class II factors.

\section{Methods}

Plant Growth Conditions and Treatments

Arabidopsis thaliana wild-type (WT), nprl-1 (Cao et al. 1994), tga1-1/tga4-1, tga3-1, tga2-1/tga3-1/tga5-1/tga6-1 (Kesarwani et al. 2007) tga-7-1, tga2-1/tga5-1/tga6-1 (Zhang et al. 2003), and sid2-2 (Wildermuth et al. 2001) plants were in Columbia (Col-0) background. Seedlings were grown in vitro in $0.5 \times$ MS medium supplemented with $10 \mathrm{~g} / 1$ sucrose and $2.6 \mathrm{~g} / \mathrm{l}$ Phytagel (Sigma) under controlled conditions $(16 \mathrm{~h}$ light, $80 \mu \mathrm{mol} / \mathrm{m}^{2} / \mathrm{s}, 22 \pm 2{ }^{\circ} \mathrm{C}$ ). For ChIP and gene expression assays, 15-day-old seedlings were floated on $0.5 \mathrm{mM} \mathrm{SA}$ (treatment) or $0.5 \times$ MS medium as a control and incubated for the indicated periods of time under continuous light $\left(80 \mu \mathrm{mol} / \mathrm{m}^{2} / \mathrm{s}\right)$. For gene expression assays, whole seedlings were immediately frozen in liquid nitrogen and stored at $-70{ }^{\circ} \mathrm{C}$ until RNA isolation. For ChIP assays, whole seedlings were processed immediately as described below. For UVB irradiation assays, 15-day-old seedlings were exposed to UVB 
light $\left(0.07 \mathrm{~mW} / \mathrm{cm}^{2}\right)$ in a chamber equipped with two USHIO UVB F8T5.UB-V, UVP 3400401 fluorescent tubes $(\lambda=$ $306 \mathrm{~nm})$. As a control, we used nonirradiated seedlings.

\section{Genetic Constructs and Plant Transformation}

Genetic constructs were generated using the Gateway technology following the manufacturer's instructions (Invitrogen). The GRXC9 promoter regions including the 5'UTR, $-1,849$ to $+26 ;-168$ to $+26 ;-112$ to +26 ; and -61 to +26 , called in the text as pC9 WT, pC9-168, pC9112 , and pC9-61, respectively, were obtained by amplification from genomic DNA, using the oligonucleotides indicated in Online Resource 8. PCR fragments were cloned into the $\mathrm{pENTR/SD/D-TOPO}$ vector and then recombined into the pKGWFS7 vector to generate transcriptional fusions with $e G F P$ and $\beta$-glucuronidase $G U S$ reporter genes (Karimi et al. 2002). Site-directed mutation of the distal and the proximal as-1-like element was performed on the $\mathrm{pC} 9$ WT promoter fragment cloned into the $\mathrm{pENTR/SD/TOPO}$ vector, as previously described (Weiner et al. 1994). The site-directed mutations generated are shown in Fig. 2c, and the oligonucleotides used to produce these mutations are listed in the Online Resource 8. The purified PCR products were recombined into the pKGWFS7 vector. In order to generate GRXC9 overexpressor lines, the GRXC9-coding region was amplified from complementary DNA (cDNA) using the primers described in the Online Resource 8. The PCR product was cloned into the $\mathrm{pENTR/SD/D-TOPO}$ vector and then recombined into the pBADcMyc vector to express the GRXC9 protein fused to a c-Myc tag controlled by the $35 \mathrm{~S}$ CaMV promoter. Final constructs were verified by sequencing and introduced into the Agrobacterium tumefaciens C58 strain. Arabidopsis plants were transformed by floral dip method. Transgenic seeds were selected in $0.5 \times$ MS solid medium supplemented with $50 \mu \mathrm{g} / \mathrm{ml}$ kanamycin for the GUS reporter lines or $15 \mu \mathrm{g} / \mathrm{ml}$ glufosinate-ammonium for the overexpressor lines. Stable homozygous transgenic lines were used for further analyses.

\section{GUS Assays}

GUS activity was determined in control- and SA-treated seedlings from each transgenic line carrying the $G R X C 9$ promoterdriven GUS constructs described above. The 4methylumbelliferyl-D-glucuronide was used as substrate, and the fluorescent product 4-methylumbelliferone was quantified, as previously described (Jefferson et al. 1987). Treatments were done by triplicate for each line, and the measurements were normalized with total protein content quantified using the Bradford assay (Bio-Rad).

\section{ChIP Assays}

ChIP assays were performed as described (Saleh et al. 2008). Five microliters of the following antibodies were used for immunoprecipitation assays: Pol II polyclonal antibody (sc-33754, Santa Cruz Biotechnology), TGA1, TGA2, and TGA3 polyclonal antibodies (Lam and Lam 1995), c-Myc polyclonal antibody (A-14, sc-789, Santa Cruz), and normal purified IgG (A2609, Santa Cruz Biotechnology) used as control of a nonspecific antibody. The concentration of DNA in each sample (input chromatin and chromatin immunoprecipitated with either specific or nonspecific antibodies) was quantified by qPCR, using the Stratagene MX3000P ${ }^{\circledR}$ equipment and the Sensimix Plus SYBR Green Reagents (Quantece). Primers used to amplify the GRXC9 promoter region containing the $a s-1$-like elements $(-212$ to +78$)$ are listed in Online Resource 8.

\section{Gene Expression Analysis}

Total RNA was obtained from frozen samples using the TRIzol ${ }^{\circledR}$ Reagent (Invitrogen) according to the manufacturer's instructions. cDNA was synthesized from each sample ( $2 \mu \mathrm{g}$ of total RNA) with an ImProm II Kit (Promega). qPCR was performed with the Stratagene MX3000 ${ }^{\circledR}$ equipment. The expression levels of GRXC9 and PR-1 were calculated relative to the YLS8 (AT5G08290) or Clathrin adaptor complex subunit (AT4G24550) genes. Primers used for each gene are listed in Online Resource 8.

\section{Yeast Two-Hybrid Assays}

The coding regions of TGA factors (TGA2, TGA5, and TGA6 and TGA3) were cloned into the pDONR201 vector (Jakoby et al. 2002). These coding regions were then recombined into the pDEST22 vector, to produce a fusion protein with the Gal4 DNA-binding domain and into the pDEST32 vector, to produce a fusion protein with the transactivation domain of the Gal4 factor. Different combinations of two constructs were used to transform the SFY526 yeast strain (harboring the Gal4RE:: $\beta$-Gal reporter construct), and qualitative assays for $\beta$-Gal activity were performed as described (Gietz and Schiestl 2007). Interaction between NPR1 and TGA2 was assayed as a positive control, and a combination of the pDEST 32 and pDEST22 empty vectors was used as a negative control.

Acknowledgments The authors thank Dr. Eric Lam (Rutgers, The State University of New Jersey, School of Environmental and Biological Sciences, Department of Plant Biology and Pathology) for providing antibodies against TGA factors.

Funding This work was supported by the National Commission for Science and Technology CONICYT (FONDECYT grant nos. 1100656 
and 1141202), the Millennium Science Initiative (Nucleus for Plant Functional Genomics, grant no. P10-062-F), and the Spanish Ministry of Science and Innovation (project number: BIO2010-14871). A.H. was supported by a PhD fellowship from CONICYT.

Open Access This article is distributed under the terms of the Creative Commons Attribution License which permits any use, distribution, and reproduction in any medium, provided the original author(s) and the source are credited.

\section{References}

Baerson SR, Sánchez-Moreiras A, Pedrol-Bonjoch N, Schulz M, Kagan IA, Agarwal AK, Reigosa MJ, Duke SO (2005) Detoxification and transcriptome response in Arabidopsis seedlings exposed to the allelochemical benzoxazolin-2(3H)-one. J Biol Chem 280(23): 21867-21881. doi:10.1074/jbc.M500694200

Benfey P, Ren L, Chua N (1989) The CaMV 35S enhancer contains at least two domains which can confer different developmental and tissue-specifi expression patterns. EMBO J 8(8):2195-2202

Blanco F, Garreton V, Frey N, Dominguez C, Perez-Acle T, Van der Straeten D, Jordana X, Holuigue L (2005) Identification of NPR1dependent and independent genes early induced by salicylic acid treatment in Arabidopsis. Plant Mol Biol 59(6):927-944. doi:10. 1007/s11103-005-2227-x

Blanco F, Salinas P, Cecchini NM, Jordana X, Van Hummelen P, Alvarez ME, Holuigue L (2009) Early genomic responses to salicylic acid in Arabidopsis. Plant Mol Biol 70(1-2):79-102. doi:10.1007/s11103009-9458-1

Borsani O, Valpuesta V, Botella MA (2001) Evidence for a role of salicylic acid in the oxidative damage generated by $\mathrm{NaCl}$ and osmotic stress in Arabidopsis seedlings. Plant Physiol 126(3): 1024-1030

Butterbrodt T, Thurow C, Gatz C (2006) Chromatin immunoprecipitation analysis of the tobacco PR-1a- and the truncated CaMV 35S promoter reveals differences in salicylic acid-dependent TGA factor binding and histone acetylation. Plant Mol Biol 61(4-5):665-674. doi:10.1007/s11103-006-0039-2

Cao H, Bowling SA, Gordon SA, Dong X (1994) Characterization of an Arabidopsis mutant that is nonresponsive to inducers of systemic acquired resistance. Plant Cell 6(11):1583-1592. doi:10.1105/tpc.6. 11.1583

Chen W, Singh KB (1999) The auxin, hydrogen peroxide and salicylic acid induced expression of the Arabidopsis GST6 promoter is mediated in part by an ocs element. Plant J 19(6):667-677. doi:10. 1046/j.1365-313x.1999.00560.x

Dong X (2004) NPR1, all things considered. Curr Opin Plant Biol 7(5): 547-552. doi:10.1016/j.pbi.2004.07.005

Dubreuil-Maurizi C, Poinssot B (2012) Role of glutathione in plant signaling under biotic stress. Plant Signal Behav 7(2):210-212. doi: $10.4161 / \mathrm{psb} .18831$

Ellis JG, Tokuhisa JG, Llewellyn DJ, Bouchez D, Singh K, Dennis ES, Peacock WJ (1993) Does the ocs-element occur as a functional component of the promoters of plant genes? Plant J 4(3):433-443. doi:10.1046/j.1365-313X.1993.04030433.x

Fan W, Dong X (2002) In vivo interaction between NPR1 and transcription factor TGA2 leads to salicylic acid-mediated gene activation in Arabidopsis. Plant Cell 14(6):1377-1389

Fode B, Siemsen T, Thurow C, Weigel R, Gatz C (2008) The Arabidopsis GRAS protein SCL14 interacts with class II TGA transcription factors and is essential for the activation of stress-inducible promoters. Plant Cell 20(11):3122-3135. doi:10.1105/tpc.108.058974

Fonseca J, Menossi M, Thibaid-Nissen F, Town C (2010) Functional analysis of a TGA factor-binding site located in the promoter region controlling salicylic acid-induced NIMIN-1 expression in Arabidopsis. Genet Mol Res 9(1):167-175

Foyer CH, Noctor G (2011) Ascorbate and glutathione: the heart of the redox hub. Plant Physiol 155(1):2-18. doi:10.1104/pp. 110.167569

Fu ZQ, Dong X (2013) Systemic acquired resistance: turning local infection into global defense. Annu Rev Plant Biol 64:839-863. doi:10.1146/annurev-arplant-042811-105606

Fu ZQ, Yan S, Saleh A, Wang W, Ruble J, Oka N, Mohan R, Spoel SH, Tada Y, Zheng N, Dong X (2012) NPR3 and NPR4 are receptors for the immune signal salicylic acid in plants. Nature 486(7402):228 232. doi:10.1038/nature 11162

Garcion C, Lohmann A, Lamodiere E, Catinot J, Buchala A, Doermann P, Metraux JP (2008) Characterization and biological function of the ISOCHORISMATE SYNTHASE2 gene of Arabidopsis. Plant Physiol 147(3):1279-1287. doi:10.1104/pp. 108.119420

Garreton V, Carpinelli J, Jordana X, Holuigue L (2002) The as-1 promoter element is an oxidative stress-responsive element and salicylic acid activates it via oxidative species. Plant Physiol 130(3):15161526. doi:10.1104/pp. 009886

Gatz C (2012) From pioneers to team players: TGA transcription factors provide a molecular link between different stress pathways. Mol Plant Microbe Interact 26(2):151-159. doi:10.1094/mpmi-04-12-0078-ia

Gietz D, Schiestl RH (2007) High-efficiency yeast transformation using the LiAc/SS carrier DNA/PEG method. Nat Protocols 2(1):31-34

Han Y, Chaouch S, Mhamdi A, Queval G, Zechmann B, Noctor G (2013) Functional analysis of Arabidopsis mutants points to novel roles for glutathione in coupling $\mathrm{H}(2) \mathrm{O}(2)$ to activation of salicylic acid accumulation and signaling. Antioxid Redox Signal 18(16):21062121. doi:10.1089/ars.2012.5052

Jakoby M, Weisshaar B, Droge-Laser W, Vicente-Carbajosa J, Tiedemann J, Kroj T, Parcy F (2002) bZIP transcription factors in Arabidopsis. Trends Plant Sci 7(3):106-111

Jefferson R, Kavanagh T, Bevan M (1987) GUS fusions: betaglucuronidase as a sensitive and versatile gene fusion marker in higher plants. EMBO J 6(13):3901-3907

Johnson C, Glover G, Arias J (2001) Regulation of DNA binding and trans-activation by a xenobiotic stress-activated plant transcription factor. J Biol Chem 276(1):172-178. doi:10.1074/jbc.M005143200

Karimi M, Inzé D, Depicker A (2002) GATEWAYTM vectors for Agrobacterium-mediated plant transformation. Trends Plant Sci 7(5):193-195. doi:10.1016/S1360-1385(02)02251-3

Kesarwani M, Yoo J, Dong X (2007) Genetic interactions of TGA transcription factors in the regulation of pathogenesis-related genes and disease resistance in Arabidopsis. Plant Physiol 144(1):336346. doi:10.1104/pp. 106.095299

Köster J, Thurow C, Kruse K, Meier A, Iven T, Feussner I, Gatz C (2012) Xenobiotic- and jasmonic acid-inducible signal transduction pathways have become interdependent at the Arabidopsis CYP81D11 promoter. Plant Physiol 159(1):391-402. doi:10.1104/pp. 112.194274

Krawczyk S, Thurow C, Niggeweg R, Gatz C (2002) Analysis of the spacing between the two palindromes of activation sequence- 1 with respect to binding to different TGA factors and transcriptional activation potential. Nucleic Acids Res 30(3):775-781

La Camera S, L'Haridon F, Astier J, Zander M, Abou-Mansour E, Page G, Thurow C, Wendehenne D, Gatz C, Metraux JP, Lamotte O (2011) The glutaredoxin ATGRXS13 is required to facilitate Botrytis cinerea infection of Arabidopsis thaliana plants. Plant $\mathrm{J}$ 68(3):507-519. doi:10.1111/j.1365-313X.2011.04706.x

Lai Z, Schluttenhofer C, Bhide K, Shreve J, Thimmapuram J, Lee S, Yun D-J, Mengiste T (2014) MED18 interaction with distinct transcription factors regulates multiple plant functions. Nat Commun 5. doi: 10.1038/ncomms4064|www.nature.com/naturecommunications 
Lam E, Lam YK-P (1995) Binding site requirements and differential representation of TGA factors in nuclear ASF-1 activity. Nucleic Acids Res 23(18):3778-3785. doi:10.1093/nar/23.18.3778

Langlois-Meurinne M, Gachon CMM, Saindrenan P (2005) Pathogenresponsive expression of glycosyltransferase genes UGT73B3 and UGT73B5 is necessary for resistance to pseudomonas syringae pv tomato in Arabidopsis. Plant Physiol 139(4):1890-1901. doi:10. 1104/pp. 105.067223

Laporte D, Olate E, Salinas P, Salazar M, Jordana X, Holuigue L (2012) Glutaredoxin GRXS13 plays a key role in protection against photooxidative stress in Arabidopsis. J Exp Bot 63(1):503-515. doi:10. 1093/jxb/err301

Lebel E, Heifetz P, Thorne L, Uknes S, Ryals J, Ward E (1998) Functional analysis of regulatory sequences controlling PR-1 gene expression in Arabidopsis. Plant J 16(2):223-233. doi:10.1046/j.1365-313x. 1998.00288.x

Lee S, Kim SG, Park CM (2010) Salicylic acid promotes seed germination under high salinity by modulating antioxidant activity in Arabidopsis. New Phytol 188(2):626-637. doi:10.1111/j.14698137.2010.03378.x

Li S, Lauri A, Ziemann M, Busch A, Bhave M, Zachgo S (2009) Nuclear activity of ROXY1, a glutaredoxin interacting with TGA factors, is required for petal development in Arabidopsis thaliana. Plant Cell 21(2):429-441. doi:10.1105/tpc.108.064477

Lieberherr D, Wagner U, Dubuis P-H, Métraux J-P, Mauch F (2003) The rapid induction of glutathione S-transferases AtGSTF2 and AtGSTF6 by avirulent pseudomonas syringae is the result of combined salicylic acid and ethylene signaling. Plant Cell Physiol 44(7): 750-757. doi:10.1093/pcp/pcg093

Maleck K, Levine A, Eulgem T, Morgan A, Schmid J, Lawton KA, Dangl JL, Dietrich RA (2000) The transcriptome of Arabidopsis thaliana during systemic acquired resistance. Nat Genet 26(4):403-410

Mateo A, Funck D, Muhlenbock P, Kular B, Mullineaux PM, Karpinski S (2006) Controlled levels of salicylic acid are required for optimal photosynthesis and redox homeostasis. J Exp Bot 57(8):1795-1807. doi:10.1093/jxb/erj196

Miura K, Okamoto H, Okuma E, Shiba H, Kamada H, Hasegawa PM, Murata Y (2013) SIZ1 deficiency causes reduced stomatal aperture and enhanced drought tolerance via controlling salicylic acidinduced accumulation of reactive oxygen species in Arabidopsis. Plant J 73:91-104. doi:10.1111/tpj.12014

Mou Z, Fan W, Dong X (2003) Inducers of plant systemic acquired resistance regulate NPR1 function through redox changes. Cell 113(7):935-944. doi:10.1016/S0092-8674(03)00429-x

Mueller S, Hilbert B, Dueckershoff K, Roitsch T, Krischke M, Mueller MJ, Berger S (2008) General detoxification and stress responses are mediated by oxidized lipids through TGA transcription factors in Arabidopsis. Plant Cell 20(3):768-785. doi:10.1105/tpc.107. 054809

Murmu J, Bush MJ, DeLong C, Li S, Xu M, Khan M, Malcolmson C, Fobert PR, Zachgo S, Hepworth SR (2010) Arabidopsis basic leucine-zipper transcription factors TGA9 and TGA10 interact with floral glutaredoxins ROXY1 and ROXY2 and are redundantly required for anther development. Plant Physiol 154(3):1492-1504. doi:10.1104/pp. 110.159111

Nawrath C, Metraux JP (1999) Salicylic acid induction-deficient mutants of Arabidopsis express PR-2 and PR-5 and accumulate high levels of camalexin after pathogen inoculation. Plant Cell 11(8):13931404

Ndamukong I, Abdallat AA, Thurow C, Fode B, Zander M, Weigel R, Gatz C (2007) SA-inducible Arabidopsis glutaredoxin interacts with TGA factors and suppresses JA-responsive PDF1.2 transcription. Plant J 50(1):128-139. doi:10.1111/j.1365-313X.2007.03039.X

Noshi M, Maruta T, Shigeoka S (2012) Relationship between chloroplastic $\mathrm{H} 2 \mathrm{O} 2$ and the salicylic acid response. Plant Signal Behav 7(8): 944-946. doi:10.4161/psb.20906
Ogawa D, Nakajima N, Sano T, Tamaoki M, Aono M, Kubo A, Kanna M, Ioki M, Kamada H, Saji H (2005) Salicylic acid accumulation under $\mathrm{O} 3$ exposure is regulated by ethylene in tobacco plants. Plant Cell Physiol 46(7):1062-1072. doi:10.1093/pcp/pci118

Qin XF, Holuigue L, Horvath DM, Chua NH (1994) Immediate early transcription activation by salicylic acid via the cauliflower mosaic virus as-1 element. Plant Cell 6(6):863-874. doi:10.1105/tpc.6.6.863

Rochon A, Boyle P, Wignes T, Fobert PR, Després C (2006) The coactivator function of Arabidopsis NPR1 requires the core of its $\mathrm{BTB} / \mathrm{POZ}$ domain and the oxidation of $\mathrm{C}$-terminal cysteines. Plant Cell 18(12):3670-3685. doi:10.1105/tpc.106.046953

Rouhier N, Lemaire SD, Jacquot JP (2008) The role of glutathione in photosynthetic organisms: emerging functions for glutaredoxins and glutathionylation. Annu Rev Plant Biol 59:143-166. doi:10.1146/ annurev.arplant.59.032607.092811

Saleh A, Alvarez-Venegas R, Avramova Z (2008) An efficient chromatin immunoprecipitation (ChIP) protocol for studying histone modifications in Arabidopsis plants. Nat Protocols 3(6):1018-1025. doi: 10.1038/nprot.2008.66

Shearer HL, Cheng YT, Wang L, Liu J, Boyle P, Després C, Zhang Y, Li X, Fobert PR (2012) Arabidopsis clade I TGA transcription factors regulate plant defenses in an NPR1-independent fashion. Mol Plant Microbe Interact 25(11):1459-1468. doi:10.1094/mpmi-09-11-0256

Stotz HU, Mueller S, Zoeller M, Mueller MJ, Berger S (2013) TGA transcription factors and jasmonate-independent COI1 signalling regulate specific plant responses to reactive oxylipins. J Exp Bot 64(4):963-975. doi:10.1093/jxb/ers389

Surplus SL, Jordan BR, Murphy AM, Carr JP, Thomas B, Mackerness SAH (1998) Ultraviolet-B-induced responses in Arabidopsis thaliana: role of salicylic acid and reactive oxygen species in the regulation of transcripts encoding photosynthetic and acidic pathogenesis-related proteins. Plant Cell Environ 21(7):685-694. doi:10.1046/j.1365-3040.1998.00325.x

Tada Y, Spoel SH, Pajerowska-Mukhtar K, Mou Z, Song J, Wang C, Zuo J, Dong X (2008) Plant immunity requires conformational changes [corrected] of NPR1 via S-nitrosylation and thioredoxins. Science 321(5891):952-956. doi:10.1126/science.1156970

Uquillas C, Letelier I, Blanco F, Jordana X, Holuigue L (2004) NPR1independent activation of immediate early salicylic acid-responsive genes in Arabidopsis. Mol Plant Mibrobe Interact 17(1):34-42. doi: 10.1094/MPMI.2004.17.1.34

Vlot AC, Dempsey DA, Klessig DF (2009) Salicylic acid, a multifaceted hormone to combat disease. Annu Rev Phytopathol 47:177-206. doi:10.1146/annurev.phyto.050908.135202

Weiner MP, Costa GL, Schoettlin W, Cline J, Mathur E, Bauer JC (1994) Site-directed mutagenesis of double-stranded DNA by the polymerase chain reaction. Gene 151(1-2):119-123. doi:10.1016/03781119(94)90641-6

Wildermuth MC, Dewdney J, Wu G, Ausubel FM (2001) Isochorismate synthase is required to synthesize salicylic acid for plant defence. Nature 414(6863):562-565. doi:10.1038/35107108

Zander M, La Camera S, Lamotte O, Métraux J-P, Gatz C (2010) Arabidopsis thaliana class-II TGA transcription factors are essential activators of jasmonic acid/ethylene-induced defense responses. Plant J 61(2):200-210. doi:10.1111/j.1365-313X.2009.04044.x

Zhang B, Chen W, Foley R, Büttner M, Singh K (1995) Interactions between distinct types of DNA binding proteins enhance binding to ocs element promoter sequences. Plant Cell 7(12):2241-2252. doi: $10.1105 /$ tpc.7.12.2241

Zhang Y, Tessaro MJ, Lassner M, Li X (2003) Knockout analysis of Arabidopsis transcription factors TGA2, TGA5, and TGA6 reveals their redundant and essential roles in systemic acquired resistance. Plant Cell 15(11):2647-2653. doi:10.1093/jxb/ers389

Zhang Y, Cheng YT, Qu N, Zhao Q, Bi D, Li X (2006) Negative regulation of defense responses in Arabidopsis by two NPR1 paralogs. Plant J 48(5): 647-656. doi:10.1111/j.1365-313X.2006.02903.x 